\title{
AMBIENTES VIRTUAIS DE APRENDIZAGEM E SUAS POSSIBILIDADES CONSTRUTIVISTAS*
}

\author{
Luciano Andreatta Carvalho da Costa \\ Sérgio Roberto Kieling Franco ${ }^{* * *}$
}

\begin{abstract}
Resumo - Toda inovação tecnológica em educação precisa se basear em um contexto epistemológico bem definido. Ao se conceber um ambiente virtual de aprendizagem AVA, deve haver com uma adequada fundamentação teórica. Assim, torna-se possível desenvolver ferramentas de aprendizagem adequadas. Neste artigo, são analisadas as possibilidades pedagógicas de ambientes virtuais de aprendizagem. Essas possibilidades são baseadas no Construtivismo, teoria proposta inicialmente por Jean Piaget. O principal objetivo do artigo é identificar de que forma cada ferramenta deve ser utilizada para se obter melhorias pedagógicas. São analisados os seguintes aspectos: a importância de uma clara definição epistemológica, a consideração de que os estudantes são protagonistas da Internet, a possibilidade de promover a autonomia do estudante, a interatividade em ambientes virtuais de aprendizagem e a aprendizagem colaborativa.
\end{abstract}

Palavras-chave: ambientes virtuais de aprendizagem, construtivismo, interatividade, aprendizagem colaborativa.

\section{Virtual learning environments and its constructivist possibilities}

\begin{abstract}
Every technological innovation in education need to be based on a welldefined epistemological context. When a virtual learning environment- AVA is conceived, an adequate theoretical foundation should be considered. Only then, it will be possible to develop adequate learning tools. In the present paper, the pedagogical possibilities of the virtual learning environments are analyzed. These possibilities are based on Constructivism, an education theory first proposed by Jean Piaget The main goal of the paper is to identify the way each tool should de used in order to obtain pedagogical advantages. The following aspects are analyzed: the importance of a clear epistemological definition, the assumption that students are protagonists of the Internet, the possibility to promote student autonomy, the interactivity through virtual learning environments and the collaborative learning.
\end{abstract}

Keywords: virtual learning environments, constructivism, interactivity, collaborative learning.

\section{INTRODUÇÃO}

O desenvolvimento de ambientes virtuais de aprendizagem - AVA's, tem se tornado uma prática constante nas pesquisas em educação a distância. Em geral, a utilização destes ambientes não exige dos professores um domínio mais aprofundado de

\footnotetext{
Artigo publicado nos anais do GCETE 2005 - Congresso Global de Educação em Engenharia e Tecnologia, realizado na cidade de Santos/SP, de 13 a 16 de março.

** Luciano Andreatta Carvalho da Costa, Universidade Estadual do Rio Grande do Sul e Centro Universitário Feevale, Av. Brasiliano Índio de Moraes, 878, apart. 18, 91030-000, Porto Alegre, RS, Brasil, luciano@uergs.edu.br

** Sérgio Roberto Kieling Franco, SEED - Ministério da Educação/ Universidade Federal do Rio Grande do Sul, Av. Paulo Gama, s/n, 90046-900, Porto Alegre, RS, Brasil, franco@edu.ufrgs.br 
informática, sendo necessárias apenas poucas horas de cursos de formação a partir do uso do ambiente.

O diferencial destas pesquisas, remete a uma análise prioritariamente pedagógica do uso deste ambiente, levando-se em conta qual a perspectiva epistemológica será adotada, permitindo assim, que se elaborem estratégias de aprendizagem. Para que se possa fazer essa análise pedagógica, será necessário relacionar os princípios teóricos que norteiam os objetivos da utilização de cada ferramenta. Ao se optar pela utilização de um trabalho em grupo a partir do ambiente, por exemplo, quais serão os fundamentos que irão definir a estratégia do professor ? Para que as estratégias sejam elaboradas, é preciso encontrar justificativas teóricas, que estejam respaldadas por uma perspectiva epistemológica bem definida. Neste artigo, será trabalhada a perspectiva construtivista, que dará respaldo às análises de alguns aspectos subjacentes à prática pedagógica, com a questão da interatividade, da aprendizagem colaborativa, da autonomia e das novas perspectivas obtidas a partir do uso da Internet e de AVA's em experiências pedagógicas.

\section{REFERENCIAL TEÓRICO}

Este artigo baseia-se na concepção construtivista acerca da aprendizagem. Tal concepção considera que o conhecimento se consolida a partir de auto-regulações que ocorrem através das relações estabelecidas entre o sujeito e o objeto. É a partir da constituição de novas relações baseadas no conhecimento prévio, que se alcançam patamares cognitivos superiores, sempre levando em consideração o caráter simultâneo e provisório da teoria piagetiana (Franco, 1999). Simultâneo por considerar o patamar inferior e superior ao mesmo tempo; e provisória, por prever patamares infinitamente superiores, sempre como constituição de relações sobre relações.

Neste contexto, alguns elementos presentes no ato educativo precisam ser reinterpretados. $\mathrm{O}$ erro, que costuma ter um caráter punitivo e inibidor, passa a ser construtivo para a aprendizagem. Ele poderá revelar elementos a respeito do processo de aprendizagem do estudante, podendo assim, auxiliar o professor nas suas estratégias de mediação. Tratar o erro como um momento privilegiado de reflexão e investigação (Ramos, 1999), considerando os mesmos como acontecimentos significativos e impulsionadores dessa prática (Souza, 2001), consiste estratégia fundamental para uma proposta de aprendizagem.

Bazzo (2000) ainda reforça que a discussão sobre os erros e acertos promove a participação ativa dos alunos, tão importante para a visão epistemológica construtivista. Mais importante que acertar a resposta é dar ênfase ao processo de elaboração da mesma (Ramos, 1999). Segundo Castorina (1988) citada por Soares et al (2001), Piaget considerava o erro mais fecundo que um acerto imediato, principalmente porque a consideração da hipótese falsa pode fornecer novos conhecimentos, quando se analisam as conseqüências dessa hipótese. $O$ erro possibilita ao professor identificar as concepções prévias dos alunos, proporcionando a base para a concepção de novas intervenções pedagógicas.

\section{ASPECTOS IMPORTANTES DE UM AMBIENTE VIRTUAL}

Para Dillenbourg (2003), um web-site educacional não é, necessariamente, um AVA. Por exemplo, disponibilizar na Internet um livro sobre construção de diagramas em estruturas isostáticas na forma de hipertexto, não apresenta maiores vantagens com relação ao próprio livro, mesmo que cada capítulo apresente exercícios com a resolução, podendo ser acessada através de hiperlinks. Da mesma forma, a utilização da tecnologia 
da realidade virtual em 3D também não garante as caraterísticas pretendidas. Utilizando o mesmo exemplo, pode-se ter uma edificação a partir da qual o usuário tem acesso com recursos da realidade virtual. Ao navegar sobre a edificação, pode-se consultar teoria e exercícios sobre a construção de diagramas em estruturas isostáticas, inclusive com diferentes animações que ilustrem os diferentes conceitos envolvidos no estudo. Essas características não são suficientes para caraterizar um AVA.

A seguir serão analisados diferentes aspectos de um AVA, para que se possa entender como um livro ou um ambiente em realidade virtual, por exemplo, podem se tornar importantes recursos de um AVA.

\section{Definição clara de uma base epistemológica}

Ao se conceber qualquer atividade pedagógica, é importante que se tenha uma clara definição epistemológica, que irá nortear o desenvolvimento das atividades propostas. Promover atividades que forneçam feedbacks imediatos para evitar que os alunos cometam erros, caracteriza uma abordagem empirista, pois funciona usualmente como uma punição ao aluno (Oliveira et al, 2001). Foi salientada no referencial teórico a importância do erro na abordagem construtivista, o que evidencia o quanto o erro do aluno pode contribuir na concepção das atividades. Os autores acima apontam como alternativa ao feedback imediato, "a inclusão de estratégias interativas de ensino que considerem o seu conhecimento prévio, aumentando assim a viabilidade de sua aprendizagem". Pode-se, por exemplo, levar o aluno a tentar entender por que resolveu daquela forma, mostrando que ela pode estar coerente com o seu conhecimento prévio. Sugere-se, também, a utilização de simulações com o objetivo de antecipar dados, possibilitando a utilização de conceitos inerentes àquele conteúdo em situações diferentes.

\section{A consideração da Internet como um espaço construído também pelos estudantes}

Dillenbourg (2003) salienta uma característica particular de ambientes virtuais, em função das particularidades da Internet. Segundo ele, os estudantes não estão restritos a consultar as informações da Rede, eles se tornam produtores da informação, participantes do jogo. A utilização de portfólios virtuais para que os alunos registrem as suas produções ao longo do curso, consiste numa atividade diferente do que entregar um trabalho apenas para o professor, pois, no primeiro caso, as informações estarão disponíveis para qualquer pessoa que tenha possibilidade de acessar a Internet ${ }^{1}$. Dessa forma, a disponibilização de um livro pelo professor pode consistir apenas o início de uma atividade que inclua os seguintes itens: a) uma pesquisa a respeito da temática abordada; b) a disponibilização, no portfólio virtual do aluno, de uma resenha a respeito do livro; c) a criação de uma lista de discussão que tenha por objetivo construir um texto coletivo a partir da análise das resenhas dos colegas; d) outras atividades que possam tornar o ambiente virtual um espaço onde os estudantes sejam efetivamente protagonistas da informação. Loiselle (2002) descreve a participação do aluno no desenvolvimento do produto, em que "o estudante conduz suas próprias operações de coleta de informações e não se coloca como um simples consumidor da informação", assim, "o dispositivo estimula os estudantes a desenvolverem um conteúdo próprio". A

${ }^{1}$ Convém destacar que no Brasil ainda é uma minoria que tem acesso à Internet. Em 2001 o IBGE (http://www.ibge.gov.br) verificou que apenas 8,6\% dos domicílios tinham microcomputadores com acesso à Internet. Esse dado retrata um problema social do Brasil, que relativiza a universalização do conhecimento através da Internet. 
partir das produções dos alunos, pode-se então enriquecer o que é chamado de dispositivo de formação multimídia (Loiselle ,2002), fazendo dele uma construção coletiva. O desenvolvimento de portfólios virtuais pelos estudantes possibilita também, segundo esse mesmo autor, um acesso a ferramentas de acompanhamento do estudante, de forma que os mesmos possam "registrar suas observações e reunir as informações necessárias que lhe pareçam essenciais", permitindo ao aprendiz "conservar indicações das leituras e atividades realizadas". Dessa forma, estimula-se que o estudante faça uma seleção das informações presentes na rede a partir de critérios por ele mesmo estabelecidos.

Um exemplo do uso do ambiente a partir de portfólios virtuais desenvolvidos pelos alunos é a experiência que descreve o uso de um tutorial chamado MAESTRO (Rojas, 2002), desenvolvido em linguagem $\mathrm{Java}^{2}$ para a disciplina Aplicações Computacionais do Curso de Pós-Graduação em Gerenciamento e Engenharia de Construção do Departamento de Engenharia Civil, Estrutural e Ambiental da Universidade de Buffalo. A interface do tutorial baseia-se na orientação para a realização de tarefas específicas solicitadas pelo estudante, como por exemplo criar um objeto 3d, alterar sua luminosidade, etc. Não é foco da disciplina uma análise aprofundada de cada um dos softwares trabalhados, em função da carga horária insuficiente. O tutorial é baseado na Internet, permitindo que seja constantemente atualizado pelo instrutor mediante o uso da linguagem html. Portfólios Virtuais são desenvolvidos por cada grupo de trabalho, que armazenam seus arquivos em diretórios do computador do instrutor, o qual pode ser compartilhado a partir de qualquer computador conectado à Internet. Propõe-se o seguinte paradigma cognitivo: educação baseada na Internet. Esse paradigma torna-se possível pois acredita-se que as tecnologias da Internet permitem um aumento na interação entre os estudantes, o que possibilitará a geração do conhecimento a partir da cooperação e do compartilhamento da informação, reforçada pelo desenvolvimento dos portfólios virtuais e pelas avaliações entre colegas ${ }^{3}$. É previsto um melhor aproveitamento do tempo na sala de aula tradicional, pois a disponibilização da informação ocorre pela web. O grande diferencial proposto por ele no desenvolvimento do ambiente, é a participação ativa do estudante no processo pedagógico criando suas próprias experiências de aprendizagem. A avaliação formativa ocorre a partir da apresentação do portfólio virtual de cada grupo, de forma que os grupos são então classificados pelos demais e por um instrutor de outro departamento, tornando os próprios estudantes participantes ativos da aprendizagem coletiva. A partir do ranking obtido, o instrutor então atribui um conceito para cada grupo com as respectivas recomendações. A avaliação somativa ocorre no final do semestre, quando o instrutor reavalia a qualidade dos trabalhos baseado nas recomendações da avaliação formativa.

Essa integração entre a proposta pedagógica e a avaliação representa um importante exemplo de coerência na condução do ato educativo, constituindo-se num forte indicador para a obtenção do sucesso na compreensão dos objetivos de aprendizagem.

\section{Possibilidade de promover autonomia ao estudante}

Inicialmente cabe situar o conceito de autonomia e suas conseqüências na concepção de um AVA. Um dos aspectos que mais diferencia a modalidade a distância da presencial é a ênfase dada na primeira ao trabalho autônomo (Fainholc, 1999). A educação a

\footnotetext{
${ }^{2}$ Java é uma linguagem de programação orientada a objetos que foi projetada para ser portável entre diferentes plataformas e sistemas operacionais. Inclui recursos especiais que o tornam ideal para programas na Internet. Permite que sejam colocados gráficos interativos em páginas da Internet.

${ }^{3}$ Formative Peer Evaluations 
distância, na perspectiva do mesmo autor, quando enfatiza a mediação pedagógica para apoiar a auto-aprendizagem do estudante, converte-se em educação aberta, proporcionando a inclusão de pessoas independentemente dos títulos acadêmicos anteriores. Assim, tem-se um modelo autogerido, estando professores e alunos separados no tempo e no espaço. Convém destacar que nem toda forma de educação a distância constitui uma modalidade de educação aberta, considerando a autonomia como eixo central dessa diferenciação. Peters (2001) relativiza, com propriedade, a autonomia nas experiências em EAD, destacando seu caráter heteronômico, sendo "predeterminado, estruturado, amarrado a fatores preestabelecidos e mais regulamentado do que o estudo com presença”, ao mesmo tempo em que o estudante trabalha autonomamente como em nenhuma outra área educacional. Os estudantes precisam assumir a responsabilidade pelo seu próprio estudo, decidindo quanto tempo, em qual intensidade e em que momento realizarão as tarefas. Segundo Peters, essa forma de autonomia "refere-se apenas à forma exterior do estudo e às suas condições diferenciadas". Todavia, a existência de prazos pré-determinados, vinculações aos semestres regulares, regras e regulamentos institucionais e restrição quanto a decisões curriculares limitam a autonomia do estudante.

A autonomia apresenta uma relação direta com o referencial teórico deste trabalho, quando se pensa sobre a forma como se estabelece a aprendizagem. Se não há, conforme foi argumentado anteriormente, a transmissão do conhecimento, e sim a sua construção ativa e baseada nas estruturas individuais do saber, a autonomia como um estudo autogerido vai ao encontro da concepção construtivista acerca do conhecimento. Basendo-se em Peters (2001) e Alava (2002), apresentam-se alguns exemplos de facetas presentes na EAD, que promovem um "espaço incomensuravelmente grande para formas do estudo autônomo e autodirigido" (Peters, 2001):

- Desonera a memória dos estudantes, em função da grande capacidade de armazenamento de dados, abrindo novas dimensões para a aprendizagem.

- Possibilita o acesso a uma grande quantidade de informação.

- Possibilita o rápido acesso a informações, o que permite a sua seleção e estruturação, facilitando sua transformação em saber. Os hiperlinks criados permitem que os alunos, a partir de seus interesses pessoais, ampliem os conhecimentos básicos do curso.

- Permite a demonstração e a comunicação dos resultados, a partir das singulares possibilidades da multimídia, tendo modos de representação múltiplos.

- Facilita a realização de análises estatísticas a partir de uma grande quantidade de dados.

- Apresenta a possibilidade de realização de atividades de aprendizagem que destaquem o papel ativo dos alunos, a partir de retornos individualizados, indicação de informações suplementares ao tema tratado e análise crítica da informação.

- Permite aos estudantes o acesso a conversações com companheiros individualmente ou com comunidades de conhecimento, sendo esta uma forma de estudo autônomo em cooperação. Estabelece-se, assim, uma rede de comunicação.

Finalmente, relaciona-se a autonomia com a Educação a Distância - EAD na medida em que amplia o espaço decisório dos estudantes, em que a busca, a compreensão e a avaliação de fontes necessárias podem ocorrer sem a presença do docente. A memorização dá lugar à pesquisa e à construção. As interfaces desenvolvidas a partir de recursos multimídia devem priorizar o "controle do aprendiz", "encorajando a exploração e o envolvimento do estudante" (Loiselle, 2002).

\section{A interatividade em AVA's}


O problema das interações representa essencialmente um contingente de ordem pedagógica (Dillenbourg, 2003). Estabelecer um ambiente colaborativo de aprendizagem não está limitado por questões técnicas, já que a utilização do correio eletrônico e dos chats, por exemplo, não apresenta maiores limitações. O desafio consiste em tornar essas comunicações em algo construtivo para a aprendizagem. Para que isso ocorra, será necessário considerar uma espécie de contrato de conversação, na maioria das vezes implícito, a ser constituído no ambiente virtual, levar em conta as diferenças entre as interações virtuais e as presenciais e considerar também as comunicações não-verbais, como o caso dos whiteboards ${ }^{4}$. Segundo Fainholc (1999), a concepção dos projetos teleducativos, a preparação dos materiais de auto-aprendizagem pedagogicamente válidos e a orientação tutorial são elementos-chave para fortalecer a interatividade. Para que os materiais informático-telemáticos sejam interativos, devem provocar, prever e prover estratégias cognitivas que sejam fatores de desenvolvimento posterior para os sujeitos a partir do trabalho autônomo, favorecendo o diálogo através de atividades capazes de desafiar o aluno. Para ela, a interatividade se alimenta a partir da elaboração de materiais contendo textos processados didaticamente, de ações tutoriais que motivem o estudante a fortalecer a sua auto-aprendizagem com trabalho didático pessoal e colaborativo com outros estudantes, que unidos sincronamente através da tecnologia, ampliam o compromisso pedagógico.

É importante, nesse contexto, refletir sobre as variáveis que determinam o nível de abertura de um AVA, o que permitirá ou não um ambiente interativo e promotor da autonomia do estudante. Módulos de ensino constituídos de unidades instrutivas autosuficientes reduzem as possibilidades da individualização do ensino, impedindo a constituição de um ambiente interativo (Fainholc, 1999). Isso não significa que as "facilidades didáticas para a aprendizagem autônoma" não tenham uma base conceitual. Dependem "do estudante que investiga intenções, revela contradições , aplica e contesta a prática". São estruturas, porém no sentido piagetiano, que incluem uma noção de totalidade, de transformação, de auto-regulação e de autoconstrução constante, dependendo, para sua transformação, das interações com o meio. Essa noção de estrutura é um sistema de transformação que, enquanto sistema, enriquece-se pelo jogo das transformações (Fainholc, 1999). Essa autora enumera alguns padrões para a concepção de materiais que promovam a interatividade, a partir de aprendizagens que satisfaçam necessidades e interesses, orientem a contextualização, apóiem-se em conhecimentos prévios e estimulem a investigação e aplicação. Para o desenvolvimento socio-emocional, propõe-se a realização de atitudes favoráveis à motivação, ao esforço pessoal, à autodisciplina e à autodedicação, e à busca compartilhada e discussão grupal. A partir das referências descritas acima, constata-se que a interatividade na EAD precisa ser entendida e considerada desde as primeiras idéias a respeito do desenvolvimento de um AVA. As peculiaridades da EAD bem como a magnitude das possibilidades da Internet remetem à constituição de um novo paradigma pedagógico, ainda não delineado por completo. Por mais correntes que estejam as aplicações em AVA's, bem como a difusão de ferramentas computacionais, ainda é necessário falar-se em novidade, quando se pensa na interatividade, na ótica construtivista, a partir da utilização de ambientes informatizados.

\section{Possibilidade de promoção da aprendizagem colaborativa}

A constituição de comunidades virtuais consiste num tema de relevante interesse para a educação, principalmente no sentido de compreender de que forma se constituirá a aprendizagem colaborativa a partir de um AVA. Fainholc (1999), referindo-se ao

\footnotetext{
4 Consiste num software a partir do qual dois ou mais usuários podem editar o mesmo documento, podendo ver, modificar e apagar os objetos editados pelos colegas [6]. 
pensamento coletivo, afirma que, "mais do que qualquer outra espécie social, dedicamonos ao pensamento coletivo e, assim procedendo, criamos um mundo de cultura e de valores que é parte integrante do nosso meio ambiente natural". Para Grabinger \& Dunlap (1996) citado por Loiselle (2002), "a presença de atividades de aprendizagem colaborativa é uma condição necessária ao estabelecimento de ambientes de aprendizagem ricos". Loiselle (2002) considera vantajoso criar redes de aprendizagens para estudantes compartilharem seus pontos de vista, seja por correio eletrônico ou por listas de discussão. Flores e Becerra (2002) apresentam estratégias de aprendizagem em colaboração mediadas por tecnologias visando à produção social do conhecimento na Universidade Virtual de Quilmes (UVQ). Nessa experiência, buscaram-se "propostas inovadoras e rigorosas de produção de materiais didáticos capazes de gerar nos estudantes processos de reflexão, análise crítica e estabelecimento de relações entre o que sabem e o novo conteúdo a aprender". Para que isso ocorra, propõe-se o "diálogo didático mediado" entre docente e aluno. Esses autores assinalam que a aprendizagem, baseada no paradigma construtivista não é resultado apenas de uma atividade autoestruturante, mas é também resultado de interações sociais, afirmando assim que o sujeito é, antes de ser um aprendiz, um sujeito social. Para tanto, será necessário construir culturalmente uma negociação de significados, que se constituirá a partir da aprendizagem colaborativa.

Particularizando para AVA's, analisa-se a aprendizagem colaborativa tecnologicamente mediada (Flores \& Becerra, 2002), afirmando que, além da aprendizagem COM a tecnologia, em que o aluno melhora seu rendimento intelectual, há a aprendizagem DA tecnologia, a partir da qual resulta um "resíduo cognitivo", obtido no processo de colaboração. Tal resíduo implica novas habilidades e novas estratégias de pensamento, com efeitos para a vida acadêmica e profissional do estudante, conforme é exemplificado a partir de uma experiência realizada em 1999, pelo curso de Licenciatura em Educação da UVQ, na disciplina "Educação e Novas Tecnologias", obrigatória e de caráter introdutório para todos os alunos do curso. No segundo trabalho prático da disciplina, ao estudar a problemática tecnologia e sociedade, foi proposto um debate entre diferentes grupos, compostos de três a quatro alunos, num total de cinqüienta, acerca de posturas tecnófilas e tecnófobas ${ }^{5}$. A cada grupo se atribuiu a defesa de uma das posturas em debate, sendo que três grupos assumiram o papel de moderadores e juízes dos debates. No primeiro caso, devia-se produzir uma argumentação da posição atribuída, a partir da bibliografia da disciplina, informações e dados coletados, etc. Já os grupos que moderaram e julgaram os debates deviam realizar um trabalho de sistematização de posturas e argumentos, para que se pudesse então dar um veredito com a postura ganhadora do debate, a partir de critérios explícitos.

A formação dos grupos e a troca de informações entre os diferentes grupos ocorreu no Fórum Aberto da Aula, um espaço de comunicação multidirecional (todos-todos) assíncrono. A publicação dos produtos elaborados por cada grupo, as discussões sobre os conteúdos próprios do trabalho e os encontros acadêmicos foram realizados nos Debates da Aula, espaço também multidirecional (todos-todos) assíncrono. No Bar da Universidade, havia a possibilidade de discussões multidirecionais (todos-todos) síncronas a respeito de argumentos a serem utilizados bem como sobre definição de tarefas. Como espaço de comunicação bidirecional e assíncrono, utilizava-se o correio eletrônico do professor e do aluno, onde se construíram coletivamente os documentos a

\footnotetext{
${ }^{5}$ Tecnófilos são aqueles que atribuem exclusivamente ao uso da tecnologia a solução dos problemas. Para alguns tecnófilos, o uso do computador na educação pode prescindir até mesmo da presença do professor. Os tecnófobos, ao contrário, têm uma aversão à tecnologia, possuindo, em alguns casos, uma visão retrógrada e sectária. 
partir de um processador de textos, enviando-se mensagens com cópias para todos os integrantes do grupo. O correio do professor foi utilizado para consultas sobre conteúdos e estratégias, sendo as respostas enviadas para todos os componentes do grupo.

A avaliação dessa experiência feita pelos seus autores foi positiva, pois foram garantidas a igualdade e a mutualidade, fundamentais para a construção social do conhecimento. Ou seja, devia haver simetria entre os papéis exercidos por cada integrante dos grupos, caracterizando a igualdade, enquanto a mutualidade se conferia a partir da existência de uma produção única, não sendo possível dividir partes dessa produção para cada integrante do grupo. Isso não significa que não houvesse diferentes papéis e diferentes tarefas no interior de cada grupo, porém, devia ser garantida a negociação de significados em torno de uma responsabilidade única. Foi considerado que a atividade resultou em conhecimento significativo para cada aluno, uma vez que a produção de argumentos deveria ocorrer sobre posturas determinadas, sendo necessário conhecê-las, e os conhecimentos prévios foram invariavelmente modificados a partir de reforços conceituais. A tradicional transmissão do conhecimento foi, segundo os autores, eliminada, uma vez que o professor agiu como um facilitador, selecionando conteúdos, estabelecendo sequiências lógicas, identificando materiais e fontes, moderando os espaços compartilhados, acompanhando os processos de produção, com a respectiva retroalimentação, e provendo informações e estratégias para a constituição de verdadeiros grupos de aprendizagem. Quanto às ferramentas disponibilizadas, foram constatadas algumas carências: a criação de fóruns multiderecionais e assíncronos para cada grupo, otimizando a utilização do correio eletrônico; salas de chat que possam ser utilizadas por diferentes grupos, podendo ser usadas privadamente por cada grupo a partir de reservas de horários; janela de produção coletiva de textos e outros softwares, onde se pode elaborar coletivamente o texto ou se compartilhar o uso de aplicativos sem a utilização do correio eletrônico.

Peters (2001) trata do mesmo tema a partir do ensino em uma comunidade de construção do conhecimento ${ }^{6}$, utilizando um computador central e a hipermídia em rede como instrumentos para um estudo autônomo e cooperativo. Cita-se o exemplo ao qual se atribui a origem desse tipo de estudo, de uma pesquisa realizada por microbiólogos. Todos trabalhavam individualmente no mesmo tema, e decidiram então informar-se mutuamente de seus progressos a partir de um PC. Daí resultou um arquivo central de cuja montagem todos participavam.

Todos participantes tiram proveito dele [documento único gerado] porque aprendem muito nesse processo, mas em um certo sentido também ensinam ao informar os outros a partir do ponto de vista de sua subdisciplina e ao acrescentar novos dados ao arquivo central (Peters, 2001).

Para que isso ocorra em experiências de aprendizagem, será necessário que os estudantes não considerem apenas o seu progresso na aprendizagem, e sim o progresso do grupo, o que pode demandar um desafio para a implementação desse tipo de construção.

\section{CONSIDERAÇÕES FINAIS}

A partir das reflexões apresentadas neste artigo, tendo como referencial teórico a concepção construtivista acerca da aprendizagem, acredita-se que a relevância pedagógica do uso de ambientes virtuais passa necessariamente pela compreensão das possibilidades de cada ferramenta doa ambientes.

\footnotetext{
${ }^{6}$ Knowledge building community

$8 \longrightarrow$ V. $3 \mathrm{~N}^{\circ} 1$, Maio, 2005
} 
$\mathrm{O}$ uso de chats, por exemplo, tornar-se-á propício à aprendizagem, se respeitar o contrato de conversação a ser estabelecido na ambiente virtual. A definição do nível de abertura de uma AVA, precisa levar em consideração aspectos relativos à promoção da autonomia do estudante, procurando-se dimensionar as atividades como estruturas no sentido piagetiano, que não reduzam as possibilidades de interação. A constituição de grupos e o uso do AVA por este grupo, precisa garantir a igualdade e a mutualidade na realização das tarefas. A construção de portfólios virtuais pelos estudantes, deve levar em consideração que aquela produção passa a integral a Internet, local onde o estudante é um doa protagonistas. A participação dos colegas nos portfólios também é facilitada pela web, a partir da inclusão de sugestões acerca dos trabalhos dos seus pares.

Por fim, sugere-se que, a partir das reflexões apresentadas, inicie-se a constituição de um marco regulador para o uso de AVA's baseados na conscepção construtivista. Este marco será melhor delineado a partir de estudos de caso e de pesquisas que façam reflexões sobro o uso de AVA's em experiências pedagógicas. 


\section{AGRADECIMENTOS}

Beneficiário de auxílio financeiro da CAPES - Brasil.

\section{REFERENCIAS}

ALAVA, S. Ciberespaço e formações abertas: rumo a novas práticas educacionais ? Porto Alegre: Artmed, 2002.

BAZZO, W. A. Educação Tecnológica: enfoques para o Ensino de Engenharia / Walter Antônio Bazzo, Luiz Teixeira, Irlan von Linsingen. - Florianópolis: Ed. da UFSC, 2000.

CAPRA, F. O ponto de mutação. 20.ed. São Paulo: Cultrix, 1997.

DILLENBOURG, P. Virtual Learning Environment. Disponível em: $<$ http://tecfa.unige.ch/tecfa/publicat/dil-papers-2/Dil.7.5.18.pdf>. Acesso em: 25 maio.2003.

FAINHOLC, B. La interactividad en la educación a distancia. Buenos Aires: Paidós, 1999

FLORES, J. \& BECERRA, M. La educación superior en entornos virtuales - el caso del programa Universidad Virtual de Quilmes. Bernal: Universidad Nacional de Quilmes, 2002.

FRANCO, S. R. K. Lógica operatória e lógica das significações em adultos do meio rural : um estudo piagetiano e seu significado educacional. 1999. 272 f. : il. Tese (Doutorado em Educação) Programa de Pós-Graduação em Educação - Faculdade de Educação, Universidade Federal do Rio Grande do Sul, Porto Alegre.

LOISELLE, J. A Exploração da Multimídia e da Rede Internet para Favorecer a Autonomia dos Estudantes Universitários na Aprendizagem . Ciberespaço e Formações Abertas - Rumo a Novas Práticas Edicacionais, Porto Alegre, Artes Médicas, 2002, p. 107-118.

OLIVEIRA. C. C.; COSTA, J. W.; MOREIRA, M. Ambientes Informatizados de Aprendizagem. Campinas: Papirus, 2001.

PETERS, O. Didática do ensino a distância. São Leopoldo: Unisinos, 2001.

RAMOS, E. M. F. O papel da avaliação educacional nos processos de aprendizados autônomos e cooperativos. In: Formação do Engenheiro, Florianópolis: Editora da UFSC, 1999. p.

ROJAS, E. M. "Use of Web-based Tools to Enhance Collaborative Learning". Journal of Engineering Education, v. 91, n.1, 2002, p. 89-96.

SOARES, E. M. S., RIBERIO, L. B. M. Avaliação Formativa: um desafio para o professor. In. CONGRESSO BRASILEIRO DE ENSINO DE ENGENHARIA, 29, 2001, Porto Alegre. Anais... Porto Alegre: Abenge, 2001.

SOUZA, D. S. G. Avaliação da Aprendizagem. Disponível em: <http://www.newtonpaiva.br/institucional/assessoriaped/doc/b22.doc>.Acesso em: 15 ago 2001. 